\title{
Co-localisation of Glandular and Squamous Cell Markers in Non-small Cell Lung Cancer
}

\author{
HIRSH KOYI ${ }^{1,2,3}$, EVA BRANDÉN ${ }^{1,2,3}$, IHSAN KASIM $^{4}$ and ERIK WILANDER ${ }^{4}$ \\ ${ }^{1}$ Department of Respiratory Medicine, Gävle Hospital, Gävle, Sweden; \\ ${ }^{2}$ Karolinska Institute, Stockholm, Sweden; \\ ${ }^{3}$ Centre for Research and Development, Uppsala University, Gävleborg Region, Gävle, Sweden; \\ ${ }^{4}$ Department of Pathology, Gävle County Hospital, Gävle, Sweden
}

\begin{abstract}
Aim: Accurate classification of lung carcinomas is crucial for selecting appropriate and adequate chemotherapy treatment. In this study, glandular (adenocarcinoma), and squamous cell differentiation were examined in non-small cell lung carcinoma (NSCLC) without obvious light-microscopic signs of squamous and glandular differentiation. Materials and Methods: All lung tumours diagnosed as NSCLC $(n=61)$, without obvious squamous or glandular features, were obtained by bronchial biopsy or core biopsy supported by computed tomography. They were diagnosed during 19962009, at the Department of Pathology, Gävle Hospital, Sweden. The tumours were examined immunohistochemically with antibodies against CK5/6, p63 (squamous cell markers) and carcinoembryonic antigen (CEA) (adenocarcinoma cell marker). Double immunostaining (p63/CEA) was also performed on individual tumours. Results: The tumours originated from 36 males and 25 females, aged 54-83 years. Pure squamous cell differentiation (CK5/6 positive only) occurred in $34.4 \%$ ( $n=21)$ tumours and pure adenocarcinoma cell differentiation (CEA positive only) was present in $14.9 \%$ $(n=9)$. Tumours with both squamous and adenocarcinoma features (CK5/6 and CEA positive) were most prevalent $(47.5 \%, n=29)$. Two tumours (3.3\%) were negative with both stains (and also synaptophysin negative). Double immunostaining (p63/CEA) revealed that squamous and adenocarcinoma markers were co-localised in cells in certain tumours. Conclusion: Co-localisation of squamous and adenocarcinoma markers in the same tumour cell suggests
\end{abstract}

Correspondence to: Hirsh Koyi, Department of Respiratory Medicine, Gävle Hospital, S-80187 Gävle, Sweden. Tel: +46 26154327, Fax: +46 26157630, Mobile: +46 70 3890101, e-mail: hirsh.koyi@regiongavleborg.se

Key Words: Lung cancer, squamous cell carcinoma, adenocarcinoma, CEA, CK5/6 expression. that additional analyses for novel biomarkers of specific lung cancer types may subsequently lead to a refined treatment choice for patients with the goal of improving clinical outcomes.

Lung cancer is the most common worldwide cause of cancerrelated death in both men and women (1-3). Despite some improvement $(2,4), 5$-year survival rates are poor, ranging from $1-9 \%$ at stage IV of the disease, when approximately $70 \%$ of patients with lung cancer are diagnosed (3-5). In Sweden, approximately 4,000 cases of lung cancer are diagnosed annually, making it the fifth most common type of cancer (6), with the highest cancer-related death rate and a 5 -year survival ranging from $12-15 \%(7,8)$.

Non-small cell lung cancer (NSCLC) accounts for $80-85 \%$ of all lung cancer types $(5,9)$ with adenocarcinoma and squamous cell carcinoma being its main histological subtypes $(1,10)$. Diagnosis of NSCLC usually occurs at a late stage due to lack of early clinical symptoms $(1,11,12)$. This invalidates surgery or radio-chemotherapy as a cure and systemic and palliative chemotherapy become important therapeutic tools that can prolong life and improve patient quality of life $(13,14)$.

Although the most common types of lung tumour are squamous cell carcinoma, followed by adenocarcinoma and small cell carcinoma, a relative increase in adenocarcinoma incidence has recently been reported in the US (15). The reason for this is unclear. In Sweden, a decline in smoking habits and exposure to radon - two factors commonly associated with both squamous cell and small cell carcinomas and other, as yet unknown, environmental factors may be involved in the relative increase of adenocarcinoma. Alternatively, both the increased use and availability of diagnostic techniques, such as immunohistochemical targeting of novel biomarkers for specific lung cancer types, may have improved tumour classification based on histological techniques. Indeed, prompt and accurate histological sub- 
classification of NSCLC is crucial in determining the optimal chemotherapy choice for patients (14) particularly in light of recently discovered, novel tumour biomarkers and molecular targets that allow for individualization of treatment so as to improve clinical outcomes $(10,12,16-18)$.

Two examples of biomarkers used to diagnose specific lung tumour types are cytokeratin (CK) $5 / 6$ and carcinoembryonic antigen (CEA). Anti-CK5/6 exhibits cytoplasmic staining and allows differentiation of squamous cell carcinoma from adenocarcinoma, whilst CEA is expressed in epithelial cell membranes and cytoplasm of cells in almost all cases of colorectal adenocarcinoma, as well as a high proportion of adenocarcinomas of the lung (19). In this study, additional immunohistochemical staining for CK5/6 and CEA in a historical collection of NSCLC biopsy samples (without obvious squamous or adenocarcinoma differentiation), and a histological diagnosis based only on routine staining with haematoxylin-eosin, were performed in order to assess the accuracy of classification of the original tumour type. The original classification of diagnosed tumour types was either confirmed or re-classified based on the outcome of immunohistochemical staining for CK5/6 and CEA.

\section{Materials and Methods}

During 1996-2009, all lung tumour-containing samples recorded in the data archive at the Department of Pathology of Gavle Hospital (Gavle, Sweden) were identified. Using the local database, all lung biopsies, both bronchial biopsies obtained at bronchoscopy and core biopsies obtained using computed tomography, originally diagnosed as NSCLC without obvious squamous cell or adenocarcinoma cell differentiation based on routine staining with haematoxylin-eosin were collected (Sympathy Data System, Tieto, Malmö, Sweden). Sixty one of these contained enough tumour material in the formalinfixed and paraffin-embedded blocks for additional immunohistochemical staining with antibodies to CK5/6 and CEA and were used in this study. The medical records and entire follow-up information for every sample were scrutinized to ensure that all samples represented primary lung tumours and not metastatic lesions.

The tissue samples were fixed in $4 \%$ paraformaldehyde $(\mathrm{pH} 7.6)$ and embedded in original paraffin blocks. Thin sections $(3.5 \mu \mathrm{m})$ were cut from these blocks, mounted on Superfrost Plus glass slides and immunohistochemically stained (Ventana Medical System OptiView DAB IHK Detection Kit 760) with monoclonal mice antibodies to CK5/6 (D5/16B4; Ventana Medical Systems Inc., Tucson, AZ, USA), CEA (CEA31; Cell Marque, Rocklin, CA, USA) and synpatophysin (a neuroendokrine antibody used to distinguish between small cell lung cancer and NSCLC). A positive control section (comprising normal skin and normal colon) was placed on each glass slide.

CK5/6 and CEA staining was then assessed and recorded for each lung biopsy sample, and tumours were confirmed as squamous cell carcinoma or re-classified accordingly based on the following grading system. Immunohistochemical reactions were graded as follows (Figure 1): Grade 0: negative reaction, grade $1+:<10 \%$ positive tumour cells, grade $2+: 10-50 \%$ positive tumour cells, grade
$3+$ : $>50 \%$ positive tumour cells. In four lung tumours with $3+$ immunohistochemistry for cells both CK5/6 and CEA, double staining was performed using p63 (nuclear staining) (4/A4; Ventana Medical Systems Inc.), and CEA (cytoplasmic staining) antibodies for studies of co-localisation of squamous and adenocarcinoma cell markers in the same cells.

\section{Results}

The tumour biopsy samples examined in this study originated from 36 males and 25 females, aged between 54 and 83 years. Seventeen biopsies had been obtained by bronchoscopy and 44 using computed tomography-guided core biopsy techniques. Table I summarizes the results of the CK5/6- and CEA-immunostaining of individual cases.

Of the 61 tumours examined, only $34.4 \%$ (21/61) were considered to be pure squamous cell carcinomas with a positive CK5/6 and a negative CEA reaction (Table II); in $86 \%(18 / 21)$ of these cases, the CK5/6 immunoreaction occurred in over $50 \%$ of tumour cells.

Tumours stained for both CK5/6 and CEA in 47.5\% (29/61) of the original tumours; CEA staining exceeded that of CK5/6 in $6.9 \%(2 / 29)$ of these cases, whilst staining was equally strong for both biomarkers in $27.6 \%$ (8/29) of cases. Of the original tumours, $14.8 \%$ (9/61) were CEA-positive only and were regarded as pure adenocarcinomas; in $44.4 \%$ (4/9) of these cases, the majority of tumour cells stained CEA-positive. In $3.3 \%(2 / 61)$ of cases, tumours were both CK5/6- and CEAnegative, as well as synpatophysin-negative, and were therefore re-classified as undifferentiated NSCLCs.

In four tumours with a majority cell population of both CK5/6- and CEA-positive staining reaction, double immunohistochemistry was performed with p63 and CEA antibodies. It was demonstrated that in these four tumours, all combinations of tumour staining occurred. Thus, colocalisation of squamous and adenocarcinoma cell markers was identified in the same tumour cells (Figure 2).

\section{Discussion}

Lung cancer is diagnosed based upon microscopic examination of small biopsies obtained at bronchoscopy or computed tomography-guided core biopsies (20) and treatment strategies have been driven by the accurate histological typing and stage at diagnosis (12). These biopsy techniques, however, tend to harvest limited tumour material, which makes tumour classification difficult. Sufficient tumour tissue is required not only for immunohistochemical stains that would determine tumour classification (14), but also for additional molecular typing that allows novel treatments, such as gefitinib and erlotinib (10, 16-18), to be targeted to individual patients with NSCLC so as to improve clinical outcomes $(10,12,16-18)$. Indeed, the advent of novel targeted treatments for NSCLC 

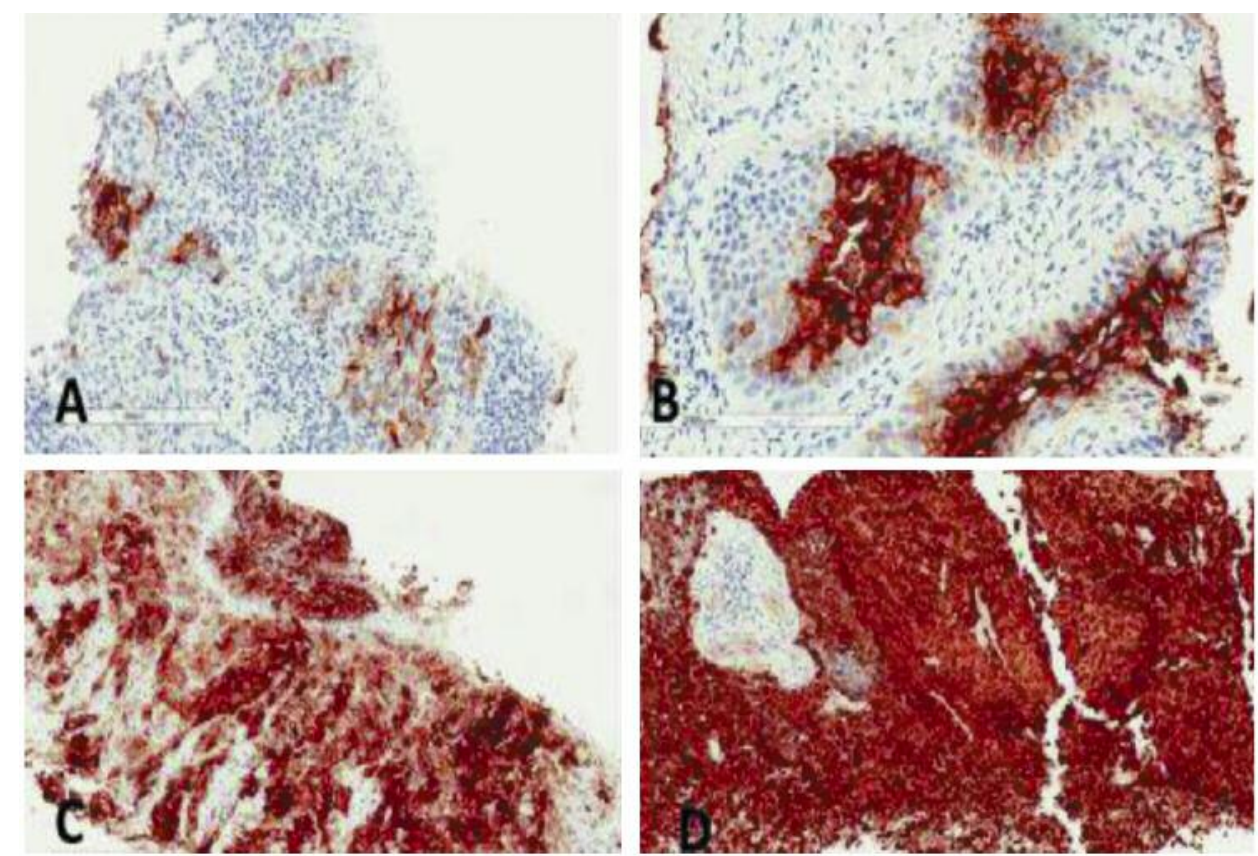

Figure 1. Immunohistochemical staining of malignant lung tumors (X80). A: Carcinoembryonic antigen (CEA) expression in case 49 (1+). B: CEA expression in case $43(2+)$. C: CEA expression in case $53(3+)$. D: Cytokeratin 5/6 expression in case $7(3+)$.

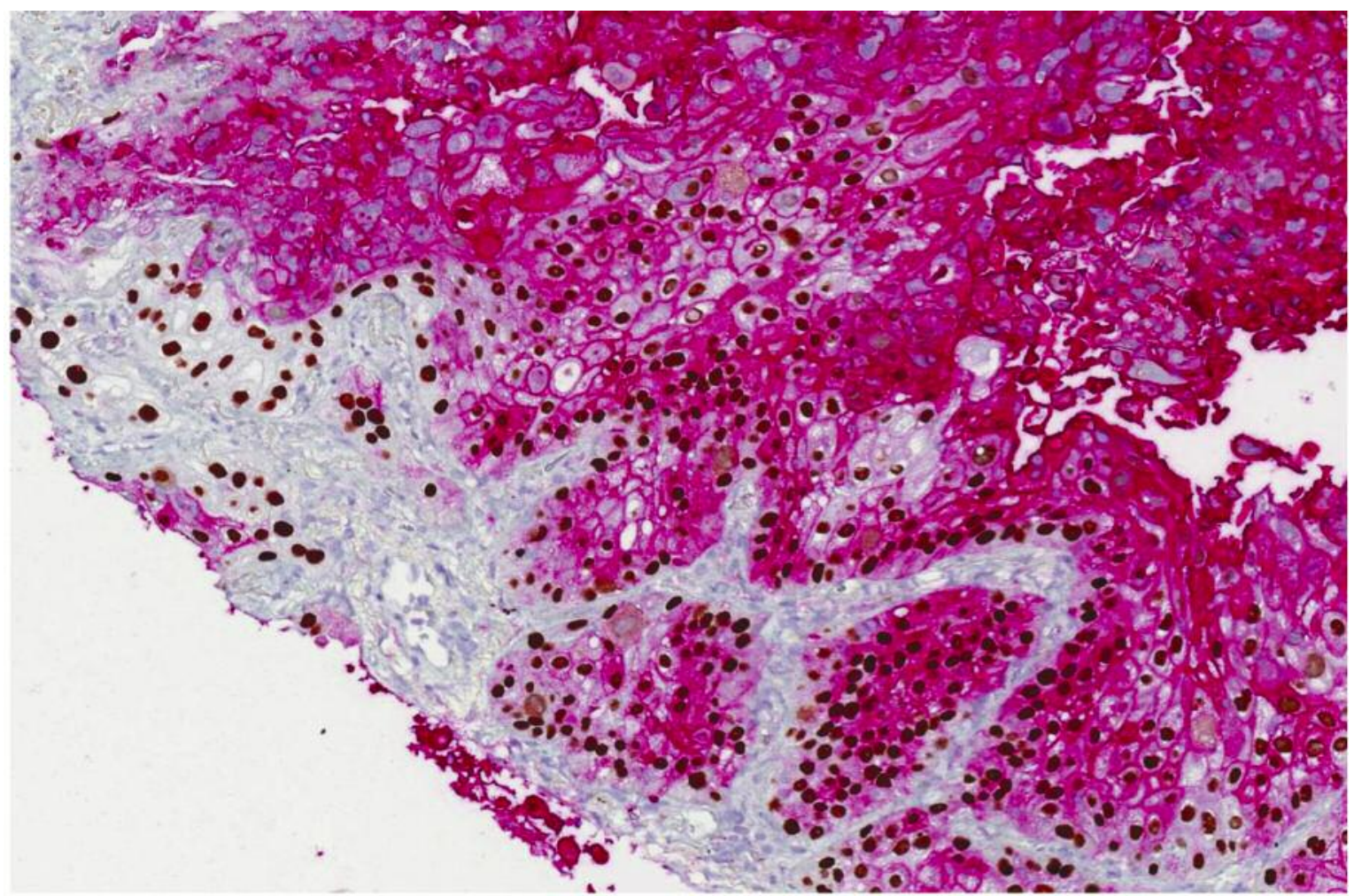

Figure 2. Lung tumour stained for p63 (brown nuclei) and carcinoembryonic antigen (CEA) (red cytoplasm). A number of tumour cells can be seen to be only p63-positive and some only CEA-positive. However, a fraction of tumour cells were both p63-and CEA-positive (blue arrow) ( $\times 200)$. 
Table I. Cytokeratin (CK)5/6 and carcinoembryonic antigen (CEA) immunoreactivity in 61 biopsies of malignant lung tumours originally diagnosed as squamous carcinomas. Grading: 0: Negative reaction, $1+$ : $<10 \%$ positive tumour cells, $2+: 10-50 \%$ positive tumour cells and $3+$ : $>50 \%$ positive tumour cells.

\begin{tabular}{|c|c|c|c|c|c|}
\hline Case no. & CK5/6 & CEA & Gender & Age (years) & Biopsy type \\
\hline 1 & $3+$ & 0 & $\mathrm{M}$ & 83 & $\mathrm{CB}$ \\
\hline 2 & $3+$ & 0 & $\mathrm{~F}$ & 81 & $\mathrm{CB}$ \\
\hline 3 & $3+$ & 0 & $\mathrm{~F}$ & 72 & $\mathrm{CB}$ \\
\hline 4 & $3+$ & 0 & $\mathrm{M}$ & 71 & $\mathrm{CB}$ \\
\hline 5 & $3+$ & $3+$ & M & 77 & $\mathrm{CB}$ \\
\hline 6 & $3+$ & $3+$ & $\mathrm{F}$ & 81 & $\mathrm{CB}$ \\
\hline 7 & $1+$ & $1+$ & $\mathrm{M}$ & 78 & $\mathrm{CB}$ \\
\hline 8 & $3+$ & $3+$ & $\mathrm{F}$ & 77 & $\mathrm{CB}$ \\
\hline 9 & $3+$ & $2+$ & M & 80 & $\mathrm{CB}$ \\
\hline 10 & $3+$ & 0 & $\mathrm{M}$ & 79 & BB \\
\hline 11 & $3+$ & $3+$ & $\mathrm{F}$ & 78 & $\mathrm{CB}$ \\
\hline 12 & $3+$ & 0 & $\mathrm{M}$ & 80 & CB \\
\hline 13 & 0 & $1+$ & $\mathrm{F}$ & 74 & $\mathrm{CB}$ \\
\hline 14 & $3+$ & 0 & F & 71 & $\mathrm{CB}$ \\
\hline 15 & $3+$ & 0 & $\mathrm{~F}$ & 80 & $\mathrm{CB}$ \\
\hline 16 & $3+$ & $2+$ & M & 78 & $\mathrm{CB}$ \\
\hline 17 & 0 & $3+$ & $\mathrm{M}$ & 72 & $\mathrm{CB}$ \\
\hline 18 & $3+$ & $2+$ & M & 71 & BB \\
\hline 19 & 0 & $2+$ & $\mathrm{F}$ & 77 & $\mathrm{CB}$ \\
\hline 20 & $3+$ & $2+$ & M & 78 & $\mathrm{CB}$ \\
\hline 21 & $2+$ & $3+$ & $\mathrm{M}$ & 76 & BB \\
\hline 22 & $3+$ & $2+$ & $\mathrm{F}$ & 74 & $\mathrm{CB}$ \\
\hline 23 & $3+$ & 0 & $\mathrm{~F}$ & 70 & $\mathrm{CB}$ \\
\hline 24 & $3+$ & 0 & $\mathrm{~F}$ & 70 & $\mathrm{CB}$ \\
\hline 25 & $3+$ & 0 & $\mathrm{M}$ & 73 & $\mathrm{CB}$ \\
\hline 26 & $3+$ & $1+$ & $\mathrm{F}$ & 71 & $\mathrm{CB}$ \\
\hline 27 & 0 & $1+$ & M & 72 & $\mathrm{CB}$ \\
\hline 28 & $3+$ & $3+$ & $\mathrm{M}$ & 69 & $\mathrm{CB}$ \\
\hline 29 & $3+$ & 0 & $\mathrm{M}$ & 75 & $\mathrm{CB}$ \\
\hline 30 & $3+$ & 0 & $\mathrm{M}$ & 67 & BB \\
\hline 31 & $3+$ & $2+$ & $\mathrm{M}$ & 63 & $\mathrm{CB}$ \\
\hline 32 & $3+$ & $1+$ & M & 72 & $\mathrm{CB}$ \\
\hline 33 & $3+$ & $1+$ & $\mathrm{M}$ & 66 & $\mathrm{CB}$ \\
\hline 34 & $3+$ & $1+$ & M & 72 & $\mathrm{CB}$ \\
\hline 35 & $3+$ & $1+$ & $\mathrm{F}$ & 66 & $\mathrm{CB}$ \\
\hline 36 & 0 & $3+$ & $\mathrm{M}$ & 69 & $\mathrm{CB}$ \\
\hline 37 & 0 & $3+$ & $\mathrm{F}$ & 66 & $\mathrm{CB}$ \\
\hline 38 & 0 & $0^{*}$ & $\mathrm{M}$ & 63 & $\mathrm{CB}$ \\
\hline 39 & $3+$ & $3+$ & $\mathrm{F}$ & 62 & BB \\
\hline 40 & $3+$ & 0 & $\mathrm{M}$ & 66 & $\mathrm{CB}$ \\
\hline 41 & $3+$ & 0 & $\mathrm{M}$ & 68 & BB \\
\hline 42 & $3+$ & $1+$ & $\mathrm{F}$ & 65 & $\mathrm{BB}$ \\
\hline 43 & $3+$ & $2+$ & $\mathrm{M}$ & 67 & $\mathrm{CB}$ \\
\hline 44 & $3+$ & $1+$ & M & 67 & $\mathrm{CB}$ \\
\hline 45 & $3+$ & $2+$ & $\mathrm{M}$ & 60 & $\mathrm{CB}$ \\
\hline 46 & $3+$ & $1+$ & $\mathrm{F}$ & 64 & $\mathrm{CB}$ \\
\hline 47 & $3+$ & $2+$ & $\mathrm{M}$ & 61 & BB \\
\hline 48 & 0 & $1+$ & $\mathrm{F}$ & 56 & $\mathrm{CB}$ \\
\hline 49 & $2+$ & $1+$ & $\mathrm{F}$ & 56 & $\mathrm{CB}$ \\
\hline 50 & 0 & $0^{*}$ & $\mathrm{~F}$ & 63 & $\mathrm{CB}$ \\
\hline 51 & $2+$ & 0 & M & 56 & $\mathrm{CB}$ \\
\hline 52 & $1+$ & 0 & $\mathrm{~F}$ & 55 & $\mathrm{CB}$ \\
\hline 53 & $3+$ & 0 & $\mathrm{~F}$ & 72 & $\mathrm{BB}$ \\
\hline 54 & 0 & $3+$ & $\mathrm{F}$ & 54 & BB \\
\hline 55 & $1+$ & 0 & $\mathrm{M}$ & 67 & BB \\
\hline 56 & $3+$ & 0 & M & 69 & BB \\
\hline 57 & $3+$ & $3+$ & $\mathrm{F}$ & 60 & BB \\
\hline 58 & $1+$ & $3+$ & M & 70 & $\mathrm{BB}$ \\
\hline 59 & $3+$ & $1+$ & M & 60 & BB \\
\hline 60 & 0 & $1+$ & M & 62 & BB \\
\hline 61 & $3+$ & 0 & M & 62 & BB \\
\hline
\end{tabular}

BB: Bronchial biopsy; CB: core biopsy; M: male; F: female. *Synaptophysin-negative.
Table II. Summary of data from Table I showing the relationship between cytokeratin (CK)5/6 and carcinoenbryonic antigen (CEA) immunoreactivity in 61 lung carcinomas originally diagnosed as squamous cell carcinomas.

\begin{tabular}{lrrrrr}
\hline & \multicolumn{5}{c}{ CK5/6, n } \\
\cline { 2 - 4 } CEA, n & 0 & $1+$ & $2+$ & $3+$ & Total \\
\hline 0 & 2 & 2 & 1 & 18 & 23 \\
$1+$ & 4 & 1 & 1 & 9 & 15 \\
$2+$ & 1 & 0 & 0 & 9 & 10 \\
$3+$ & 4 & 1 & 1 & 7 & 13 \\
Total & 11 & 4 & 3 & 43 & 61 \\
\hline
\end{tabular}

has increased the demand for adequate, high quality, tumour tissue samples obtained with minimally invasive techniques for prompt and accurate diagnosis, staging and treatment selection $(14,20)$.

In this study, tissue samples were sufficient to allow a reexamination of the haematoxylin-eosin-stained sections of lung tumours diagnosed as squamous cell carcinoma with additional immunohistochemistry. The results showed that the original diagnosis, which had been based on exclusion of tumours that lacked both the typical features of small cell lung carcinoma and signs of adenocarcinoma differentiation, such as glandular and papillary structures, was somewhat arbitrary. Most tumours were solid with only the occasional, obvious sign of squamous cell differentiation.

Whilst staining for thyroid transcription factor 1 (TTF-1) and tumour protein $\mathrm{p} 63$ have been advocated as the first step in differentiating between adenocarcinoma and squamous cell carcinoma, respectively (14), only two biomarkers were selected here due to limited availability of biopsy material: CK5/6 because it is considered to be the most relevant, sensitive and specific marker for squamous cell differentiation of lung squamous cell carcinoma (21-23), and CEA because it is a sensitive marker for demonstrating adenocarcinoma differentiation (24). Other biomarkers that can also stain tumour cells with squamous cell differentiation are TTF- 1 and napsin-A. The TTF- 1 biomarker is a $38-\mathrm{kDa}$ nuclear protein encoded by a gene located on chromosome $14 \mathrm{q} 13$ and a master regulatory transcription factor for tissuespecific genes (25). It is expressed in the thyroid, lung and diencephalon during embryogenesis and plays a decisive role in the maintenance of functions of terminal respiratory unit cells in the normal lung (26-28). Napsin-A, a novel aspartic proteinase of the pepsin family, is a highly sensitive and specific marker of lung adenocarcinoma (29-30), with the occasionally reported disadvantage of diminished expression in poorly differentiated tumours (31). Whilst CEA is the 
most sensitive marker for adenocarcinomas of the lung, its disadvantage is its low specificity (24); for example, most gastrointestinal adenocarcinomas typically stain positively for CEA. In this study, however, CEA specificity was of minor importance since all examined tumours were almost certainly not of metastatic origin.

The 61 lung tumours of this study originally had been classified as squamous cell carcinomas based on tumour morphology using microscopy analysis of haematoxylineosin-stained sections. After immunostaining with CK5/6 and CEA and re-analysis, only $34.4 \%$ (21/61) were still considered to be pure squamous cell carcinomas, due to positive CK5/6 and negative CEA staining. The majority of tumours $(47.5 \%, 29 / 61)$ stained positively for both CK5/6 and CEA and, therefore, were classified as mixed adenocarcinoma and squamous cell carcinomas. In two $(6.9 \%)$ of these mixed cases, the frequency of CEA-positive cells clearly exceeded the CK5/6-positive cells, and in eight cases (27.6\%), the CEA- and CK5/6-positive cells were equal in number. Nine (14.8\%) tumours stained CK5/6-negative and CEA-positive and were re-classified as adenocarcinomas. Two (3.3\%) tumours stained CK5/6-, CEA- and synaptophysin-negative and were considered to be undifferentiated carcinomas.

This study clearly demonstrated the difficulty in describing lung tumours using traditional histological terms. Tumours are often phenotypically heterogenic and tumour cells may display a variety of staining properties with immunohistochemistry. Therefore, both qualitative and quantitative measurements must be used to describe and accurately classify malignant lung tumour biology. This is particularly important in light of recent advances in targeted therapies for specific lung tumour types, which allow individualization of treatment based on molecular typing to improve clinical outcomes. This study shows that histological classification of small cell lung biopsies using haematoxylin-eosin-stained sections is insufficient, but can be improved using additional immunohistochemical staining to more accurately diagnose the lung cancer type.

\section{Acknowledgements}

Dr. Grażyna Söderbom from Klipspringer provided medical writing support.

\section{References}

1 Folch E, Costa DB, Wright J and VanderLaan PA: Lung cancer diagnosis and staging in the minimally invasive age with increasing demands for tissue analysis. Transl Lung Cancer Res 4: 392-403, 2015.

2 Dela Cruz CS, Tanoue LT and Matthay RA: Lung cancer: epidemiology, etiology, and prevention. Clin Chest Med 32: 605644, 2011

3 Molina JR, Yang P, Cassivi SD, Schild SE and Adjei AA: Nonsmall cell lung cancer: epidemiology, risk factors, treatment, and survivorship. Mayo Clin Proc 83: 584-594, 2008.
4 Schabath MB, Thompson ZJ and Gray JE: Temporal trends in demographics and overall survival of non-small-cell lung cancer patients at Moffitt Cancer Centre from 1986 to 2008. Cancer Control 21: 51-56, 2014.

5 Salgia R: Diagnostic challenges in non-small-cell lung cancer: an integrated medicine approach. Future Oncol 11: 489-500, 2015.

6 SoS Cancer Incidence, 2013. https://www.socialstyrelsen.se/ Lists/Artikelkatalog/Attachments/19613/2014-12-10.pdf.

7 Socialstyrelsen, Nationella riktlinjer for lungcancervard, 2011. http://www.socialstyrelsen.se/publikationer 2011/2011-3-2.

8 Socialstyrelsen. Cancerincidens i Sverige 2012. Nya diagnosticerade cancerfall ar 2012. Sveriges Officiella Statistik, statistik - halso- och sjukvard. 2014. http://www.socialstyrelsen.se/ publikationer2013/2013-12-17.

9 Koyi H, Hillerdal G, Andersson O, Kölbeck KG, Liv P and Brandén E: Chemotherapy treatment of elderly patients $(\geq 70$ years) with non-small cell lung cancer: A seven-year retrospective study of real-life clinical practice at Karolinska University Hospital, Sweden. Lung Cancer Int 2015: 317868, 2015

10 Kulesza P, Ramchandran K and Patel JD: Emerging concepts in the pathology and molecular biology of advanced non-small cell lung cancer. Am J Clin Pathol 136: 228-238, 2011.

11 Koyi H, Hillerdal G and Branden E: A prospective study of a total material of lung cancer from a county in Sweden 19971999: gender, symptoms, type, stage, and smoking habits. Lung Cancer 36: 9-14, 2002.

12 Jung CY: Biopsy and mutation detection strategies in non-small cell lung cancer. Tuberc Respir Dis (Seoul) 75: 181-187, 2013.

13 NSCLC Meta-Analyses Collaborative Group: Chemotherapy in addition to supportive care improves survival in advanced nonsmall-cell lung cancer: a systematic review and meta-analysis of individual patient data from 16 randomized controlled trials. J Clin Oncol 26: 4617-4625, 2008.

14 Ho C, Tong KM, Ramsden K, Ionescu DN and Laskin J: Histologic classification of non-small-cell lung cancer over time: reducing the rates of not-otherwise-specified. Curr Oncol 22: 164-170, 2015.

15 Houston KA, Henley SJ, Li J, White MC and Richards TB: Patterns in lung cancer incidence rates and trends by histologic type in the United States, 2004-2009. Lung Cancer 86: 22-28, 2014.

16 Domvri K, Zarogoulidis P, Darwiche K, Browning RF, Li Q, Turner JF, Kioumis I, Spyratos D, Porpodis K, Papaiwannou A, Tsiouda T, Freitag L and Zarogoulidis K: Molecular targeted drugs and biomarkers in NSCLC, the evolving role of individualized therapy. J Cancer 4: 736-754, 2013.

17 Ma PC: Personalized targeted therapy in advanced non-small cell lung cancer. Cleve Clin J Med 79: 56-60, 2012.

18 Araki T, Yashima H, Shimizu K, Aomori T, Hashita T, Kaira K, Nakamura $\mathrm{T}$ and Yamamoto K: Review of the treatment of nonsmall cell lung cancer with gefitinib. Clin Med Insights Oncol 6: 407-421, 2012.

19 Rousserie G, Grinevich R, Brazhnik K, Even-Desrumeaux K, Reveil B, Tabary T, Chames P, Baty D, Cohen JH, Nabiev I and Sukhanova A: Detection of carcinoembryonic antigen using single-domain or full-size antibodies stained with quantum dot conjugates. Anal Biochem 478: 26-32, 2015.

20 Koyi H, Johansson L, From J and Nyrén S: Biopsy testing in an inoperable, non-small cell lung cancer population - a retrospective, real-life study in Sweden. J Thoracic Disease 7: 2226-2233, 2015. 
21 Kaufmann O, Fietze E, Mengs J and Dietel M: Value of p63 and cytokeratin $5 / 6$ as immunohistochemical markers for the differential diagnosis of poorly differentiated and undifferentiated carcinomas. Am J Clin Pathol 116: 823-830, 2001.

$22 \mathrm{Chu}$ PG and Weiss LM: Expression of cytokeratin 5/6 in epithelial neoplasms: an immunohistochemical study of 509 cases. Mod Pathol 15: 6-10, 2002.

23 Terry J, Leung S, Laskin J, Leslie KO, Gown AM and Ionescu DN: Optimal immunohistochemical markers for distinguishing lung adenocarcinomas from squamous cell carcinomas in small tumour samples. Am J Surg Pathol 34: 1805-1811, 2010.

24 Sheahan K, O'Brien MJ, Burke B, Dervan PA, O'Keane JC, Gottlieb LS and Zamcheck N: Differential reactivities of carcinoembryonic antigen (CEA) and CEA-related monoclonal and polyclonal antibodies in common epithelial malignancies. Am J Clin Pathol 94: 157-164, 1990.

25 Guazzi S, Price M, De Felice M, Damante G, Mattei MG and Di Lauro R: Thyroid nuclear factor 1 (TTF-1) contains a homeodomain and displays a novel DNA binding specificity. EMBO J 9: 3631-3639, 1990.

26 Downey P, Cummins R, Moran M and Gulmann C: If it's not CK5/6 positive, TTF-1 negative it's not a squamous cell carcinoma of lung. APMIS 116: 526-529, 2008.

27 Johansson L: Histopathologic classification of lung cancer: Relevance of cytokeratin and TTF-1 immunophenotyping. Ann Diagn Pathol 8: 259-267, 2004.
28 Nakamura N, Miyagi E, Murata S, Kawaoi A and Katoh R: Expression of thyroid transcription factor-1 in normal and neoplastic lung tissues. Mod Pathol 15: 1058-1067, 2002.

29 Hirano T, Auer G, Maeda M, Hagiwara Y, Okada S, Ohira T, Okuzawa K, Fujioka K, Franzén B, Hibi N, Seito T, Ebihara Y and Kato H: Human tissue distribution of TA02, which is homologous with a new type of aspartic proteinase, napsin A. Jpn J Cancer Res 91: 1015-1021, 2000.

$30 \mathrm{Kim}$ MJ, Shin HC, Shin KC and Ro JY: Best immunohistochemical panel in distinguishing adenocarcinoma from squamous cell carcinoma of lung: tissue microarray assay in resected lung cancer specimens. Ann Diagn Pathol 17: 85-90, 2013.

31 Stoll LM, Johnson MW, Gabrielson E, Askin F, Clark DP and Li QK: The utility of Napsin-A in the identification of primary and metastatic lung adenocarcinoma among cytologically poorly differentiated carcinomas. Cancer Cytopathol 118: 441-449, 2010 . 